\title{
The expression of social experience in a figure placement task'
}

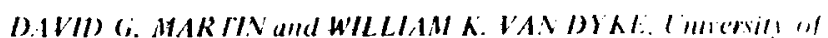
lowa. Lowa (it!. lowa 5ב240)

Thirt. femule Ss interacted with either a hostils rejecting $E$ (IIRE) or a jrichally accepting $E(F A E)$ prior to comple'ting figure placcment tasks. Results supported $(p<.05)$ the hypothesis that the IIRE condition would elicit an avoidance resplonse which would be displaced to the figure placement task, resulting in greater distunce between figures. It was predicted that this separation effect would be greater with the figure placement task most similar to the experimental situation. This was not found, although results were in the predicted direction and one of two comparisons approached significance.

In a series of studies, Kuethe $(1962 a, b)$ has investigated "social schemas" through the usc of a figure placement task in which an $S$ arranges human silhouettes and/or geometric forms on a felt board. Kuethe and others have reported correlational evidence (Kuethe, 1962a, b; Kuethe, 1964; Kuethe \& Stricker. 1963; Kuethe \& Weingartner, 1964; Levinger \& Gunner, 1967; Weinstein, 1965; Carlson \& Price, 1966) showing that many of the arrangements of figures have high commonality. indicating that Ss have used the same "schemas" as the basis of these responses. For example, horizontal distance between figures has been interpreted as reflecting approach or avoidance.

All of these results have been interpreted to mean that past social experiences are the determinants of figure placement responses. This interpretation requires, however. that the investigators have accurately specified the nature of the social history of their Ss through their selection procedure and that the aspects of the history which they specified are in fact those determining the figure placement response. The present study was an attempt to provide experimental evidence for the position that social experiences are reflected in figure placement tasks.

A second unresolved issue is that of specifying the mechanism by which social experiences are reflected in the figure placement task. The present study was designed to demonstrate that the concept of displacement can be used as a possible explanation of the consistent pattern found in figure arrangements. Incorporating the stimulus generalization model of displacement (Miller. 1948). this reasoning led to the further prediction that the displaced response would be reflected most strongly in the available (figure placement) response which most closely resembled the original response.

To test this formulation two predictions were made: (1) Ss exposed to a hostile rejecting E (HRE) will displace an avoidance response to the figure placement task by placing the figures farther apart than Ss exposed to a friendly accepting E. (FAE). and (2) the greater the similarity between the figure placement task and the experimental situation the greater will be the effect predicted in Hypothesis 1. A third prediction, to replicate one of Kuethe's findings, was that (3) Ss in the FAE (control) condition will place a male and female closer together than two male figures.

\section{SUBJECTS}

Thirty female introductory psychology students were randomly assigned to either the FAE or HRE condition.

\section{INSTRUMENTS AND STIMULUS MATL RIALS}

Four two-dimensional cut-out figure pairs were used: a man-man pair (MM), a man-woman pair (MW), a man-girl pair (MG), and a woman-girl pair (WG). Four two-dincensional 8-1/2 $x$ 11 in. seenes (living room. lield, strect and blank) were used as the field on which these figures were to be placed.

As a cover task for the hostile or friendly interaction of the experimental condition a questionnaire composed of three questions concerning "controversial" current chent topics was adninistered orally to each $S$.
In an attempt to obtain an externat measure al Ss' reaction (o) I (sec procedures), after the experiment $S$ filled out several questionnaires to indicite her reaction to $E$ and to the procedure. bRO(T)UR!

All Ss had signed up for an experiment entitled "Social Perception." tach $S$ was met by the same male $E$ who behaved in either a harsh rejecting manner or in a friendly itcepting manner. depending on the condition to which $S$ had been assigned. The E's behavior was based on a script which had been rehcarsed 20 times for each condition and which had been tried out on two Ss beforc the beginning of data collection.

Under the HRE condition. $E$ arrived $5 \mathrm{~min}$ late and curtly instructed $S$ to come to the experiment. When $E$ and $S$ reached the door of the experimental room, E "discovered" a young woman (accomplice) sitting at his desk. The $S$ then observed $E$ harshly and rudely reprimanding the accomplice, who left meckly and apologetically. After being seated in the experimental room, $E$ rudely administered the "Controversial Topics Questionnaire" in which he asked $S$ for her opinions on three controversial issues. The $E$ then read the directions for the figure placement task in a harsh and perfunctory manner. During the time $S$ was placing the figures, E maintained silence, to avoid any systematic "verbal conditioning" of Ss" behavior. The $\mathrm{E}$ recorded the figure placements in such a way to permit later reconstruction of the picture. Under the FAE condition the same procedure was followed with differences in E's behavior designed to make him friendly and accepting toward both $S$ and the accomplice.

As all Ss left the experimental room and walked down the hall, they were asked by a second female accomplice to fill out a questionnaire that the psychology department was using to ascertain students reactions to various experiments. The true purpose of this questionnaire was to obtain an external measure of the expected avoidance reaction to $E$ under the HRE condition. Following this all Ss were thoroughly debriefed and pledged to secrecy about the experiment.

RESULTS

The design used was a Type VI analysis of variance (conditions by figure pairs by backgrounds) following Lindquist (1956).

The first prediction, that $S s$ in the HRE condition would place figures farther apart (mean $=6.8 \mathrm{~cm})$ than would $S s$ under the FAE condition (mean $=4.6 \mathrm{~cm})$, was supported $(F(1,28)=4.99$, $p<.05$ ).

The second hypothesis, that similarity between figure pairs and the experimental situation would be related positively to the HRE separation effect was analyzed in two ways (see Table 1). Comparing only the MW and MM figure pairs, it was predicted that the HRE separation effect would be stronger with the MW pair since it was more similar to the experimental situation. The prediction of such an interaction was not supported $(F(1.84)=.8685)$ but the results were in the predicted direction. A similar analysis was curried out for the MG and WG figure pairs with the greatest separation effect predicted for the MG figure

Table 1

Means and Standard Deviations of Distance Between Members of all Figure Pairs for HRE and FAE Conditions

\begin{tabular}{|c|c|c|c|c|}
\hline \multirow[b]{2}{*}{ HRE Condition } & \multicolumn{4}{|c|}{ Figure Pair } \\
\hline & MM & $\mathrm{MW}$ & $\mathrm{MG}$ & WG \\
\hline \multirow{3}{*}{$\begin{array}{l}\mathrm{N}=15 \text { Mean } \\
\mathrm{SD}\end{array}$} & 7.112 & 5.605 & 7.802 & 6.680 \\
\hline & 3.23 & 4.116 & +.19 & 3.57 \\
\hline & & & & \\
\hline \multirow{2}{*}{$\begin{array}{c}N=15 \text { Mean } \\
\text { SD }\end{array}$} & 0.200 & 3.562 & +.068 & 4.708 \\
\hline & $2.6 ?$ & 2.17 & 2.22 & 4.23 \\
\hline
\end{tabular}


pair. The predicted interaction was not found $(F(1,84)=2.27$, $.05<p<.10$ ) but the results approached significance and were in the predicted direction.

The third hypothesis, that all Ss would place a male and a female figure closer together (mean $=3.56$ ) than two male figure $($ mean $=6.20)$, was supported $(t(28)=1.952, p<.05)$.

Analysis of the effect of background used revealed no significant effects; all $F$ values were less than 1.0. On the post-experimental questionnaires, $S$ s in the HRE condition rated both the experiment and the experimenter in more negative terms, and significantly more often and more strongly expressed a desire to avoid the experimenter (all comparisons significant beyond the .001 level).

\section{DISCUSSION}

The first hypothesis, that an experimentally induced avoidance response would result in greater distance between figures in a figure placement task, was supported. This result supports Kuethe's assumption that past experience and learning are expressed in such a task and suggests that previous experimenters have been correct in interpreting horizontal distance between figures as a reflection of approach or avoidance. A question left unanswered by the present study is that of determining the mechanism through which social experience is expressed in the figure placement task. The present findings do not clearly support displacement as the mechanism operating but do not rule it out either, since both of the displacement-based predictions were in the predicted direction and one approached significance. These results, however, must be replicated before displacement can be postulated as the operative mechanism and other mechanisms ruled out. It is conceivable, for example, that some sort of content-free "separation set" was evoked by the HRE condition.
That is, there could have been a tendency for the Ss in the HRE condition to separate to a greater extent any two objects, whether they were representations of human figures or some nonsocial objects such as geometric shapes.

\section{REFERENCES}

CARLSON, R., \& PRICE, M. A. Generality of social schemas. Journal of Personality \& Social Psychology, 1966, 3, 589-592.

KUETHE, J. L. Social schemas. Journal of Abnormal \& Social Psychology, $1962 a, 64,31-38$.

KUETHE, J. L. Social schemas and the reconstruction of social object displays from memory. Journal of Abnormal \& Social Psychology. 1962b, $65,71.74$.

KUETHE, J. L. The pervasive influence of social schemata. Journal of Abnormal \& Social Psychology, 1964, 68, 248-254.

KUETHE, J. L., \& STRICKER, G. Man and woman: Social schemata of males and females. Psychological Reports, 1963, 13, 655-661.

KUETHE, J. L., \& WEINGARTNER, N. Male-female schemata of homosexual and nonhomosexual penitentiary inmates. Journal of Personality, 1964, 32, 23-31.

LEVINGER, G., \& GUNNER, J. The interpersonal grid: 1. Felt and tape techniques for the measurement of social relationships. Psychonomic Science, 1967, 8, 173-174.

LINDQUIST, E. F. Design and analysis of experiments in psychology and education. Boston: Houghton Mifflin Company, 1956.

MILLER, N. E., \& BUGELSKI, R. Minor studies in aggression: The influence of frustration imposed by the ingroup on attitudes expressed toward out-groups. Journal of Psychology, 194, 25, 437-442.

WEINSTEIN, L. Social schemata of emotionally disturbed boys. Journal of Abnormal Psychology, 1965, 70, 457.461.

\section{NOTE}

1. This article is based on the junior author's Master's thesis. 